\title{
REVIEW
}

\section{The role of the androgen receptor as a driver and mitigator of cellular stress}

\author{
Dimitrios Doultsinos ${ }^{1}$ and lan Mills $\mathbf{s}^{1,2}$ \\ ${ }^{1}$ Nuffield Department of Surgical Sciences, John Radcliffe Hospital, University of Oxford, Oxford, UK \\ 2Patrick G Johnston Centre for Cancer Research, Queen's University of Belfast, Belfast, UK
}

Correspondence should be addressed to D Doultsinos: dimitrios.doultsinos@nds.ox.ac.uk

\begin{abstract}
Prostate cancer is a high-incidence male cancer, which is dependent on the activity of a nuclear hormone receptor, the androgen receptor (AR). Since the AR is required for both normal prostate gland development and for prostate cancer progression, it is possible that prostate cancer evolves from perturbations in AR-dependent biological processes that sustain specialist glandular functions. The archetypal example of course is the use of prostate specific antigen (PSA), an organ-type specific component of the normal prostate secretome, as a biomarker of prostate cancer. Furthermore, localised prostate cancer is characterised by a low proliferative index and a heterogenous array of somatic mutations aligned to a multifocal disease pattern. We and others have identified a number of biological processes that are AR dependent and represent aberrations in significant glandular processes. Glands are characterised by high rates of metabolic activity including protein synthesis supported by co-dependent processes such as glycosylation, organelle biogenesis and vesicle trafficking. Impairments in anabolic metabolism and in protein folding/processing will inevitably impose proteotoxic and oxidative stress on glandular cells and, in particular, luminal epithelial cells for which secretion is their primary function. As cancer develops there is also significant metabolic dysregulation including impaired negative feedback effects on glycolytic and anabolic activity under conditions of hypoxia and heightened protein synthesis due to dysregulated PI 3-kinase/mTOR activity. In this review we will focus on the components of the AR regulome that support cancer development as well as glandular functions focussing on the unfolded protein response and on regulators of mTOR activity.
\end{abstract}

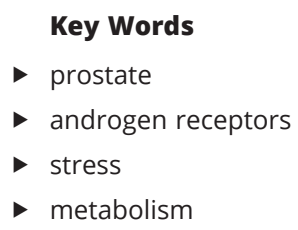

Journal of Molecular Endocrinology (2020) 65, R19-R33
The prostate gland - dealing with a heavy workload

The prostate gland is a highly metabolically active organ. Secretory luminal prostate cells within the gland are net citrate secretors to provide citrate as a metabolite, which supports ATP production to support sperm viability. In this sense the TCA cycle, which would otherwise oxidise citrate for aerobic respiration in other cell types, is impaired.
Prostate cells in the untransformed healthy prostate are able to carry out this function due to their capacity to store zinc through the overexpression of the ZIP1 zinc transporter, which allows zinc accumulation to inhibit citrate oxidation (Eidelman et al. 2017). This property of untransformed prostates points to a basal ATP production 
mechanism dependent on glycolysis akin to a Warburg effect when compared to other tissues (Barfeld et al. 2014). Such secretory output and glycolytic activity require high protein demand and protein turnover and as such an increased protein folding capacity. Secretory proteins are indispensable in this process and their processing and folding occurs in the endoplasmic reticulum (ER). Proteins may be misfolded while assuming their tertiary and quaternary 3D conformation and as such may be programmed for refolding or for terminal degradation. At any given point, the ER has a certain capacity for coping with misfolded proteins. If the amount of misfolded proteins exceed this threshold, a physiological phenomenon occurs which is termed ER stress. There is a designated homeostatic mechanism designed to deal with misfolded protein induced ER stress called the unfolded protein response (UPR). As its name suggests, this mechanism attempts to clear the ER of misfolded proteins through a few different functional outputs that include halting translation, increasing folding capacity and expanding the ER. The UPR is extremely important in the life cycle of a cell as it acts as a death or adaptation rheostat against adverse conditions. As such if the UPR is overwhelmed, the cell undergoes apoptosis (Almanza et al. 2018). Naturally this plays significant roles not only in normal physiology (B cell expansion, insulin production) but also in disease; a hyper-adaptive UPR confers high survival selectivity to the cells that possess it (such as cancer), while a constantly overwhelmed UPR leads to mass dysfunction and thus degeneration (such as loss of islets of Langerhans in diabetes) (Doultsinos et al. 2017).

\section{The androgen receptor - a key player in prostate physiology}

The androgen receptor (AR) is a transcription factor that upon androgen binding regulates gene transcription through crosstalk with transcription factors, nuclear translocation and response element binding eliciting both genomic and non-genomic activities. It is tethered to the cytoplasm by filamin $\mathrm{A}$, and binding of androgens such as DHT induces conformational changes in the AR to form an activation function binding surface (Bennett et al. 2010). The AR is paramount to prostatic development. In vivo studies where the $\mathrm{AR}$ has been knocked out (ARKO mouse models) have shown that, in its absence, mice are aprostatic, while it has been shown that AR expression in the prostate is a late developmental event mostly associated with terminal prostatic morphogenesis
(Heinlein \& Chang 2004). The AR is most highly expressed in luminal epithelial cells (Bonkhoff \& Remberger 1993) which carry out highly secretory specialised functions in producing proteins such as the prostate specific antigen (PSA) that is the major diagnostic biomarker in prostate cancer (Hoffman 2011). As a transcription factor itself, it has a gene regulatory network aligned to the expression and function of proteins associated with this specialised differentiation function that comprises glycolytic and anabolic metabolism, glycosylation, calcium and lipid metabolism and protein folding either by direct binding or by proximity effects on neighbouring genes (Massie et al. 2011, Barfeld et al. 2014). This effect is recapitulated in localised prostate cancer (Gorlov et al. 2009). There is evidence then that as prostate cancer develops the AR takes on the role of a transcriptional regulator for other gene networks but can also maintain biological processes that are advantageous to cancer development. These include glycosylation, lipid turnover and stress-relieving adaptation and reprogramming mechanisms in adverse conditions (hypoxia, glucose deprivation) elicited by the tumour microenvironment, such as the UPR (Cultrara et al. 2018). The AR is very much implicated in multiple metabolic disorder pathophysiologies. As far as metabolic malignancies are concerned both prostate and breast cancer (BCa) fall under the remit of hormone sensitive neoplasms. Indeed, there is certain overlap between the two disease states with the AR being shown to play a significant role in BCa development. It does this by inducing proliferation, while in $\mathrm{PCa}$, although ADT is effective in over $80 \%$ of cases, patients with CRPC develop treatment resistance mechanisms that include non-canonical androgen production, AR gene and/or protein upregulation among others (ProverbsSingh et al. 2015).

\section{The UPR and the ER stress response}

The UPR signals through three major transducers: PKRlike endoplasmic reticulum kinase (PERK), activating transcription factor 6 (ATF6) and, the most evolutionarily conserved across species, inositol requiring enzyme 1 (IRE1) (Fig. 1). According to one model of UPR activity, the luminal domains of these three ER resident transducers, when inactive, are bound to UPR sensor BiP (or GRP78, HSP70). BiP, alongside protein disulphide isomerases PDI4-6, senses misfolded proteins and binds onto them, releasing the three UPR transducers to assume their active state conformations (Bertolotti et al. 2000, Eletto et al. 2014). In the case of IRE1 and PERK, this involves 


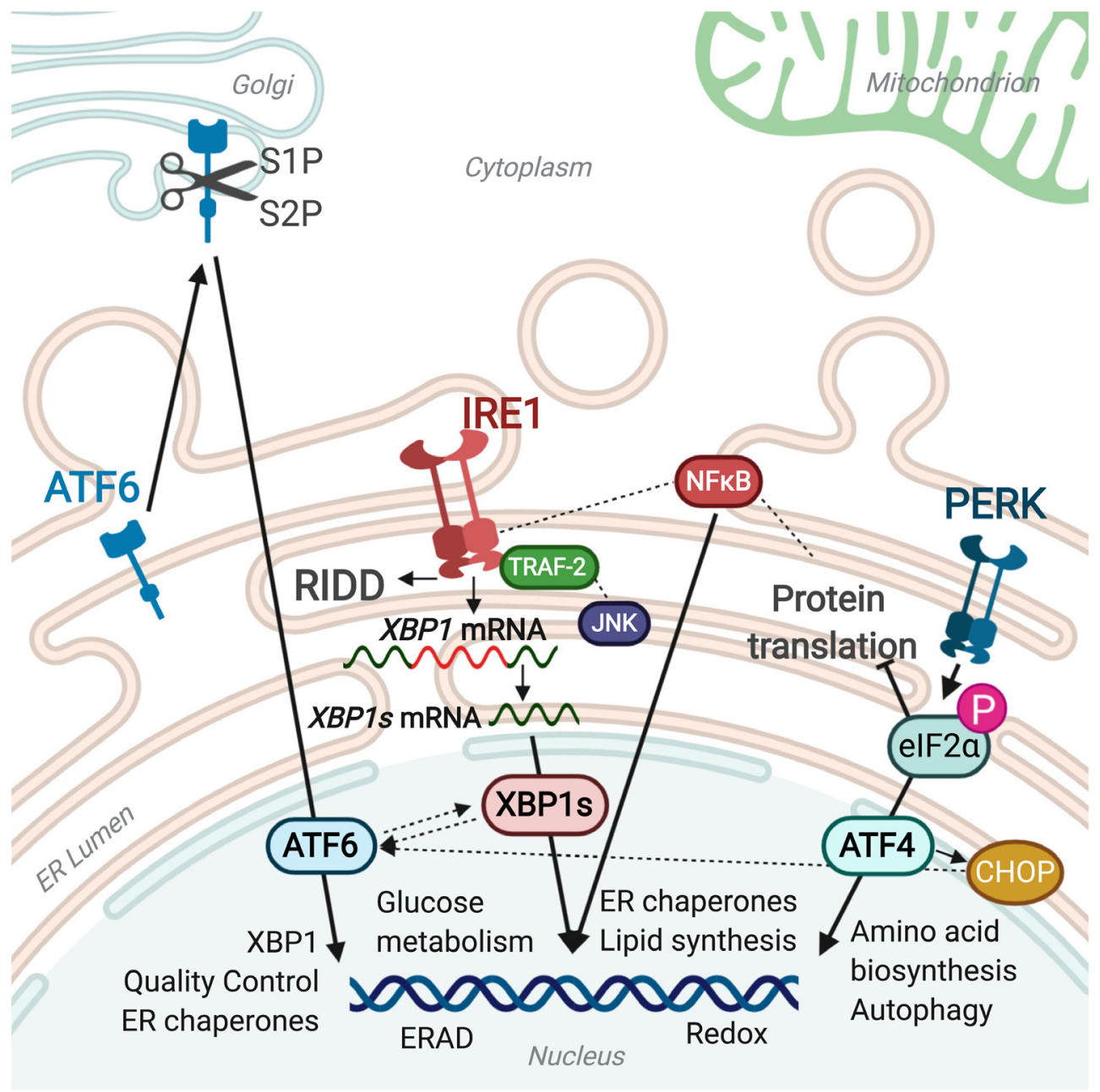

Figure 1

The unfolded protein response. The three main UPR transducers IRE1, PERK and ATF6 signal through transcription factors XBP1s, ATF4 and ATF6, respectively, to the nucleus to initiate responses to deal with misfolded protein induced ER stress. The interconnected nature of the three transducers is illustrated. Both IRE1 and PERK are implicated in the UPR associated NFkB pathway, ATF6 and XBP1s are reciprocally regulated and ATF4-induced CHOP impacts ATF6 signalling. In addition, IRE1 is essential for TRAF-2 and JNK signalling (Rothe et al. 1995, Urano et al. 2000). In the presence of genetic and physiological stress drivers, a physiologically normal cell would be overwhelmed and signal for apoptosis. Cancer cells utilise a hyper-adaptive UPR to survive.

autophosphorylation and oligomerisation, while in the case of ATF6 it involves the unveiling of an ER export motif that allows its translocation to the Golgi. All three sensors give rise to transcription factors that signal to the nucleus to induce various processes that attempt to resolve ER stress such as cessation of translation and increased folding capacity (Fig. 1).

IRE1 is dual enzyme, encompassing both serine/ threonine kinase and endoribonuclease activity. When BiP dissociates from IRE1, it utilises its kinase to transautophosphorylate and oligomerise. This allows a conformational change that activates the RNase domain which has two distinct functional outputs as well as induce JNK and TRAF signalling (Cheng et al. 2014,
Zhu et al. 2014). First, it unconventionally cleaves the mRNA of XBP1 to produce XBP1s, a transcription factor that signals to the nucleus to induce mechanisms designed to deal with ER stress (Lee et al. 2008). Secondly, it degrades a distinct subset of mRNAs and miRNAs to either decrease the rates of subsequent protein synthesis or release the brakes in gene expression imposed by miRNAs on other targets through a process termed RIDD (Hollien et al. 2009) (Fig. 1). IRE1 exists in two isoforms IRE1 $\alpha$ (hereafter referred to as IRE1) and IRE1 $\beta$ (Imagawa et al. 2008). Although IRE1 $\alpha$ is ubiquitously expressed, IRE1 $\beta$ is only found in mucosal epithelia in the gastrointestinal and pulmonary tracts (Martino et al. 2013). Recently, it was shown that IRE1 $\beta$ is negatively regulating IRE1 $\alpha$ 
in a dominant negative manner as IRE1 $\beta$ lacks the trans-autophosphorylation and oligomerisation capacity that IRE1 $\alpha$ needs to exert its RNase mediated influence on cell physiology (Grey et al. 2020).

PERK, when activated, phosphorylates eIF2 $\alpha$ which restricts translation by inhibiting eukaryotic translation initiation factor 2B (eIF2B) activity and as such reduces protein load. Inhibition does not extend to activating transcription factor 4 (ATF4) which synergises with CHOP to promote terminal UPR activities that involve signalling for apoptosis (Flaherty et al. 2014) (Fig. 1). Indeed PERK is not the only eukaryotic initiation factor associated kinase that is involved in these signalling pathways. Protein kinase R (PKR) affects NFkB as well as eIF2 $\alpha$ and has been shown to have tumour suppressive functions impacting cell growth and proliferation (Garcia et al. 2006). Additionally, general control non-de-repressible 2 (GCN2) is an important sensor of the integrated stress response (ISR), which is a common adaptive homeostatic pathway with the phosphorylation of eIF $2 \alpha$ at its epicentre (Pakos-Zebrucka et al. 2016). GCN2 induces ATF4 translation in response to perturbations in proteostasis including amino acid deprivation and can, in turn, impact on immunological and inflammatory responses (Ye et al. 2010, Xia et al. 2018).

ATF6 (the least studied UPR transducer), after being translocated to the Golgi, is being cleaved and induces the production of transcription factor ATF6f which among other functionalities can induce the expression of IRE1 and CHOP to complement and enhance the activity of the other two UPR arms, collectively contributing to pathological processes such as oncogenicity (Dadey et al. 2016) (Fig. 1).

The UPR through its transducers and downstream transcription factors activates certain ER stress related pathways such as ubiquitin-proteasome or lysosomal dependent protein degradation. These involve ER associated degradation (ERAD) and autophagy, respectively (Kruse et al. 2006). XBP1s and ATF6 push ERAD to attempt to clear misfolded proteins from the ER by translocating them to the cytosol to be proteasomally degraded. ERAD signalling is complemented by autophagy. When accumulation of misfolded proteins overwhelms ERAD, autophagy is induced to deal with large molecule and organelle degradation through autophagosome sequestration which is then fused with the lysosome (Tasdemir et al. 2008). This pathway seems to be more eIF $2 \alpha$ and JNK signalling dependent and as such contribute further to apoptotic cell death (Tcherpakov et al. 2009).
The extent to which these biologies are relevant to the survival and progression of cancer is closely linked to the metabolic and genomic dependencies of each disease state they are involved in.

\section{Roles of UPR in cancer}

The UPR shapes both normal- and patho-physiology of different cell types through its stress response elements, but it also has unconventional roles in disease progression. $\mathrm{PCa}$ is the commonest male cancer and displays a specific dependence on androgen metabolism through the AR (Heinlein \& Chang 2004). Inhibition of the AR by secondor first-generation anti-androgens is the standard of care in PCa with some success; over $80 \%$ of patients respond to treatment.

AR expression and UPR activity have been correlated and this may well be due to potential interplay between the two biochemical cascades, but also due to an accumulation of AR protein aggregates in the cytoplasm. During mouse embryonic cell differentiation, it was shown that BiP interacts with the AR and is recruited into AR cytoplasmic aggregates to induce the UPR, while at the same time AR overexpression saw an exacerbated generalised ER stress response that promoted apoptosis with cells displaying a differentiation phenotype also showing an overabundance of AR aggregates (Yang et al. 2013). Sensing of misfolded proteins is carried out by chemical chaperones such as protein disulphide isomerases (PDIs). One such dimeric protein, AGR2, is involved in intestinal inflammation and promotes the development of inflammatory disorders when disrupted, as it causes imbalances in the ER homeostatic microenvironment through autophagy or secretion of AGR2 itself (Maurel et al. 2019). Its little known paralogue, AGR3, has also been shown to have pro-tumoral properties, as it is involved in micro-environmental signalling processes that impact Src mediated cancer cell migration and adhesion (Obacz et al. 2019). Interestingly, both AGR2 and AGR3 have been shown to be androgen responsive genes and transcriptionally upregulated in prostate cancer cells possibly due to the observation that both AGR2 and AGR3 sequences comprise binding sites for the androgen receptor on the distal promoter and intron regions, respectively (Bu et al. 2013) (Fig. 2). It is therefore evident that AR and the UPR interact in both a direct and indirect manner and that AR driven cancers such as PCa have a hyper-adaptive UPR to deal with the stress.

The IRE1-XBP1 axis of the UPR is also particularly relevant to sustaining AR activity in prostate cancer. 
By genetic targeting XBP1 and IRE1 as well as the use of IRE1 small molecule inhibitors, the IRE1-XBP1 axis has been shown to support tumorigenesis in pre-clinical models of prostate cancer. In the same study, ADT was shown to downregulate the expression of IRE1-XBP1 target genes and enhance pro-apoptotic signalling through the PERK-ATF4 arm and downstream CHIP/DDIT3 (Storm et al. 2016). Collectively, this suggests that IRE1/XBP1 biology is important in untransformed prostate glands and sustains prostate cancer development prior to perturbing AR signalling. In order to more specifically target UPRdependent pro-survival factors, it would be helpful to have a more refined view of the UPR-driven sub-biologies that are most required for AR-dependent tumorigenesis. Lessons can be learned from studies in other cancer types and model systems.

For example, IRE1 has been shown to govern cytoskeleton remodelling and cell migration through interacting with filamin $\mathrm{A}$, which acts as an interphase interactor between the dynamic actin cytoskeleton and the UPR (Urra et al. 2018). This pertains to the probability of crosstalk between the UPR and many other biochemical pathways that may be targetable in a multitude of conditions (Hetzet al. 2013) that include a diverse repertoire of cancers. Indeed, tumours are constantly exposed to both intrinsic and extrinsic perturbants that include genomic instability, inflammation, immune cell invasion and nutrient deprivation. In addition, they undergo stressful processes such as endothelial mesenchymal transition (EMT) and differentiation/reprogramming to induce cancer cell invasion and metastasis, angiogenesis and treatment resistance, all of which have been associated with the utility of the UPR (Urra et al. 2016). Depending on the cancer type, the nature of the oncogenes involved and the treatment history of the cancer, there can be differential dependencies on different UPR axes but also, importantly, on different subcomponents/sub-biologies regulated by those axes. XBP1 has been shown to promote triple negative breast cancer (TNBC) by promoting a hypoxia driven, HIF1 $\alpha$ mediated pathophysiology associated with poor prognosis (Chen et al. 2014) and IRE1 inhibition sensitised TNBC cells to paclitaxel (Logue et al. 2018). Conversely, in glioblastoma (GBM), it was demonstrated that XBP1 signalling confers worse prognosis than RIDD signalling in GBM patients and, when taken into the context of tumour aggressiveness based on angiogenesis, invasion and immune infiltration, these two functional outputs of IRE1 seemed to play a dual and even antagonistic role in tumour progression (Lhomond et al. 2018). The implication of this work is that the regulation of lineage differentiation represents an impertinent UPR-dependent process fundamental to understanding the outcome for cancers treated with UPR inhibitors. Determining the extent to which this is also true in prostate cancer and the mechanistic basis for it if it is true will be a vital component of future UPR research in this and other cancer types.

By contrast, a much more established UPR-regulated 'sub-biology' is ERAD. ERAD has been positively linked with PCa tumorigenesis, as it has been shown that ERAD components are practically non-existent in normal prostate epithelial lines while significantly upregulated in cancerous cells; an effect also observed in patient derived tissue. Interestingly, the androgen responsive ERAD component, SVIP, was shown to be an endogenous ERAD inhibitor that is downregulated by androgen treatment; something not observed with almost any other component such as Ufd2a, Derlin1 and Npl4 (Erzurumlu \& Ballar 2017) (Fig. 2).

ERAD itself can support the turnover of lipids, proteins and other 'metabolites'. We know that as prostate cancer develops, unlike other cancer types, there is a metabolic switch associated with enhanced oxidative metabolism. This correlates with the hypermethylation of the ZIP1 transporter promoter leading to a zinc deficient phenotype in PCa thereby overcoming zinc-accumulation-mediated cytotoxicity (Renty 2014) (Fig. 2). Additional modified biochemical process include enhanced TCA cycle activity, reduced citrate secretion, reduced polyamide secretion and enhanced oxidative stress (Herroon et al. 2018). Cells manage this by transforming their energy production to oxidise citrate, in order to produce ATP through the Krebs cycle, as an early event in prostatic transformation (Costello \& Franklin 2000, Cutruzzolà et al. 2017). Moreover, there is deregulated lipid metabolism and increased lipid turnover, studies showing that there is an alternative fatty acid desaturation pathway to the established palmitate metabolism that dually contribute to cancer cell proliferation (Vriens et al. 2019). Fatty acid metabolism and fatty acid oxidation (FAO), in particular, have been singled out as pharmacological targets in PCa. CDK9 inhibition, for example, has been shown to lead to accumulation of acyl-carnitines, which, being FAO intermediates, induced acute metabolic stress. Blocking this pathway showed promise for synthetic lethality, and further studies showing that ER stress inhibits FAO in the liver may provide other therapeutic avenues of synthetic lethality involving AR targeting, FAO targeting as well as UPR modulation (DeZwaan-McCabe et al. 2017) (Fig. 2). 


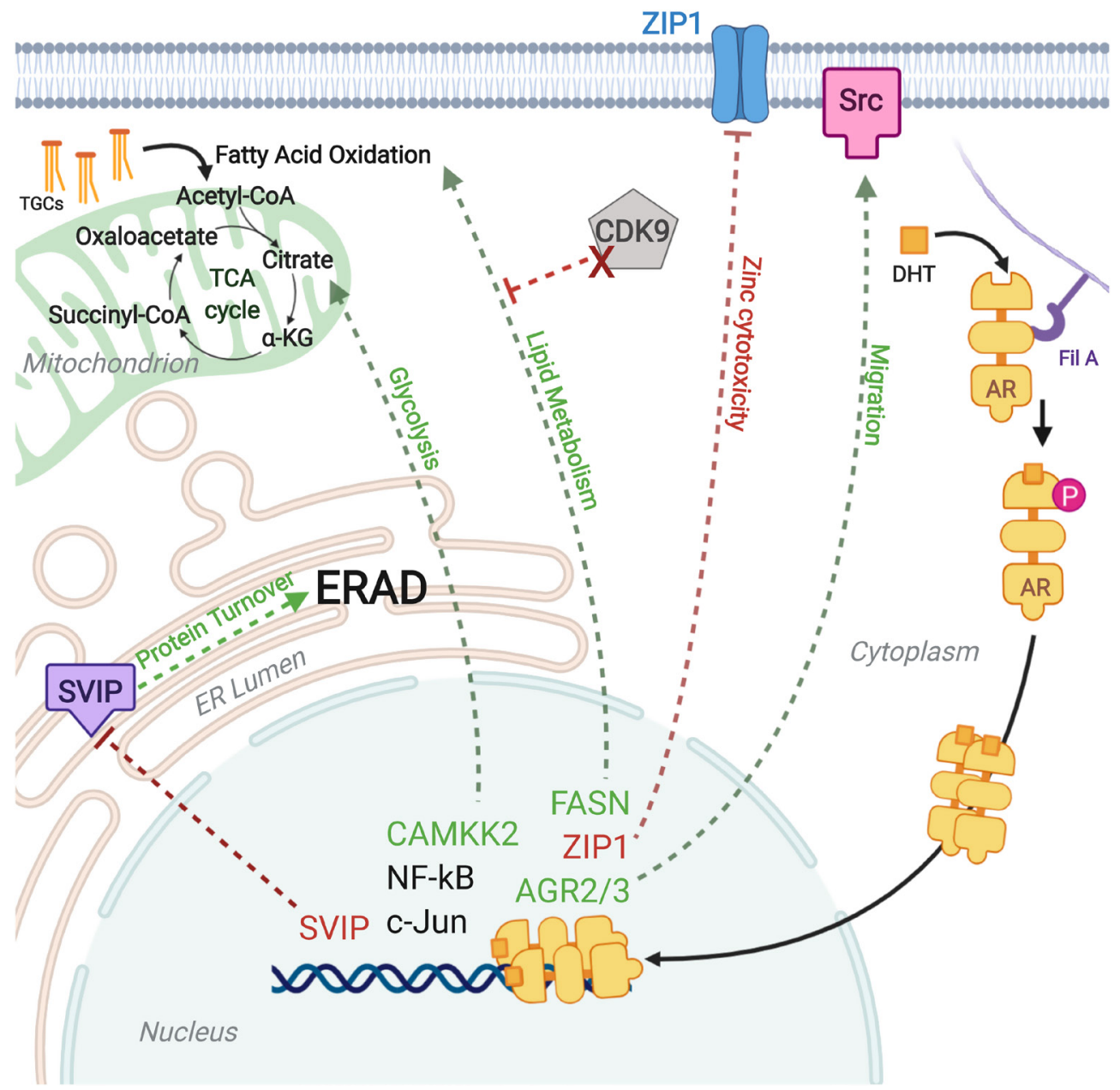

Figure 2

The androgen receptor in hormone sensitive prostate cancer. Metabolic effect of AR genomic signalling on prostate cancer early development. Green and red arrows and letters, respectively, represent genes and pathways upregulated or downregulated by the AR. AGR2/3, FASN and CAMKK2 induction lead to migration through Src signalling, lipid metabolism through FAO and glycolysis through citrate production, respectively. Conversely, the downregulation of ERAD inhibitor SVIP leads to ERAD induction, while the downregulation of zinc transporter ZIP1 reduces intracellular zinc accumulation and toxicity. Associated mechanisms include NFkB and JNK pathways (Zhang et al. 2009, Xu \& Hu 2020). These mechanisms aid prostate cancer cells to overcome metabolic stress and proliferate.

Here too it is clear that the greatest potential to exploit the UPR to treat cancers can only arise from an understanding of the co-dependency between the UPR and other important mediators of cancer progression, in this case lipid metabolism. In exceptionally poor-prognosis cancers such as GBM, developing a refined understanding of this will maximise outcomes for patients. Prostate cancer by contrast is characterised by a very good prognosis for the majority of localised cases, and consequently having learnt more about these relationships, the first translational opportunities will arise in end-stage disease, sometimes referred to as castrate-resistant prostate cancer (CRPC).

Based on this switch we would predict that UPRdependent biologies including lipid droplet biogenesis, antioxidant prediction and lipidic ERAD would be necessary complementary homeostatic/pro-survival processes. This more refined understanding of UPR dependency is lacking in localised/untreated prostate cancer, in part, due to the lack of pre-clinical models of early-stage disease.

\section{CRPC}

Prostate cancer progression to CRPC occurs in a minority of diagnosed cases over a period of several years and often downstream of radical treatment and treatment with androgen deprivation therapy/anti-androgens (Hussain et al. 2018). Unlike localised prostate cancer, it shows many of the Hallmarks of other poor-prognosis cancer types including a high incidence of somatic mutations 
in classical drivers of tumorigenesis such as $\mathrm{p} 53, \mathrm{Rb}$ and c-Myc. As a result, significant progress has been made in sub-typing CRPC according to these mutational profiles through initiatives such as StandUp2Cancer. Genomic drivers and mutations identified through these studies and others include PTEN-loss, p53/Rb loss and Myc amplification/overexpression (Grasso et al. 2012) (Fig. 3). In addition, hypoxic signalling, which in part is due to HIF1 $\alpha$ activation, also supports the evolution of CRPC, and hypoxic gene signatures can prognostic localised prostate cancers as can mutational profiles (Ranasinghe et al. 2013). PTEN and c-Myc are currently the best studied in the context of UPR activity in prostate cancer and it is helpful to summarise this.

\section{PTEN-loss is an mTOR activator compounding AR signalling}

PTEN-loss confers enhanced PI3k/Akt signalling and downstream mTOR activation (Edlind \& Hsieh 2014) which in turn elicits an increased protein load and subsequent homeostatic mechanisms designed to deal with it. The ER is exceptionally important in metabolic processes, and mTOR is a signalling pathway paramount to various physiological processes including energy metabolism, autophagy, apoptosis, translation and inflammation. Studies suggest that the predominant role of mTOR signalling is to suppress autophagy dependent survival during terminal ER stress, while inhibition of this pathway has been shown to induce the UPR in models of sarcoma (Kapuy et al. 2014, Briggs et al. 2017). Specifically, it seems that mTOR signalling may regulate IRE1 signalling by modulating its endoribonuclease dynamic response through mitochondria-ER contact site remodelling dynamics, potentially taking advantage of ER membrane expansion and its utility in protein quality control travel routes in and out of mitochondria (SanchezAlvarez et al. 2017, Hansen et al. 2018). Furthermore, it is a pathway that has been implicated in the development and maintenance of CRPC through the PI3K-AKT-mTOR signalling axis (Fig. 3).

There is a direct link between this and the AR signalling cascade with a dynamic interplay between the two contributing to disease exacerbation. In fact, hyperactivation of this pathway is sufficient to induce PCa formation with the involvement of mTORC1 and 2 being essential for this to occur in vivo (Edlind \& Hsieh 2014). It has though been shown that PI3K-AKT-mTOR is not only in interplay but also more dominant than the AR pathway in PCa cells. Inhibition of PI3K activated AR signalling but unexpectedly the resulting effects were anti-proliferative, while at the same time the mTOR inhibitor rapamycin activated AR target genes synergistically with androgen (Kaarbø et al. 2010). mTORC2, in particular, seems to balance AKT activation through its interplay with eIF2 $\alpha$ eliciting responses from the PERK arm of the UPR. Phosphorylation of eIF2 $\alpha$ at S51 guides cell fate decisions dependent on AKT (Rajesh et al. 2015). Inhibition of mTORC2 induces eIF2 $\alpha$ S51P which in turn depends on the activation of AKT promoting survival during stress (Tenkerian et al. 2015). As such, there is a clear link between protein synthesis, the UPR and AR signalling in PCa that could be exploitable in sensitising CRPC tumours by synthetic lethality mechanisms (Fig. 3). Indeed, mTOR inhibitors have been implicated in CRPC, as progression to CRPC from PCa may be a result of somatic changes to the PI3K-AKT-mTOR pathway. Unfortunately, overall inhibitors proved to be inefficacious in treating CRPC with feedback mechanisms between AR signalling and PI3K signalling being potential reasons for this (Statz et al. 2017). Since ADT or mTOR inhibition are inadequate in CRPC as monotherapies, the addition of UPR modulation could provide a novel therapeutic adjuvant approach to established therapies. Synthetic lethality has been proposed in advanced $\mathrm{PCa}$ in the form of PARP inhibition due to data pointing to homologous recombination defects in such tumours. Upon ADT therapy, PARPmediated repair mechanisms are upregulated, which could mean that inhibiting PARP alongside ADT would provide a genetic cell state unable to cope with DNA strand breaks (Asim et al. 2017). PTEN-loss is also supporting cholesteryl ester/lipid droplet storage, which could act as a substrate reservoir for steroid hormone synthesis as such, pointing to lipid accumulation as a prognostic factor of $\mathrm{PCa}$ (Fig. 3). Indeed, accumulation resulting from exogenous lipoprotein influx and cholesterol ester storage positively regulates PCa proliferation, invasion and growth (Yue et al. 2014).

\section{Tumorigenesis driven by PTEN mutation and metabolic dysregulation is supported by UPR signalling}

Advanced stage prostate cancer is predominantly found to present with bone metastasis and even after ADT remains androgen dependent. During these metastatic processes, $\mathrm{Ca}++$ metabolism is of paramount importance and is mediated by serine threonine intracellular kinases such as CAMKK2. This protein was found to be significantly overexpressed in malignant prostate glands 


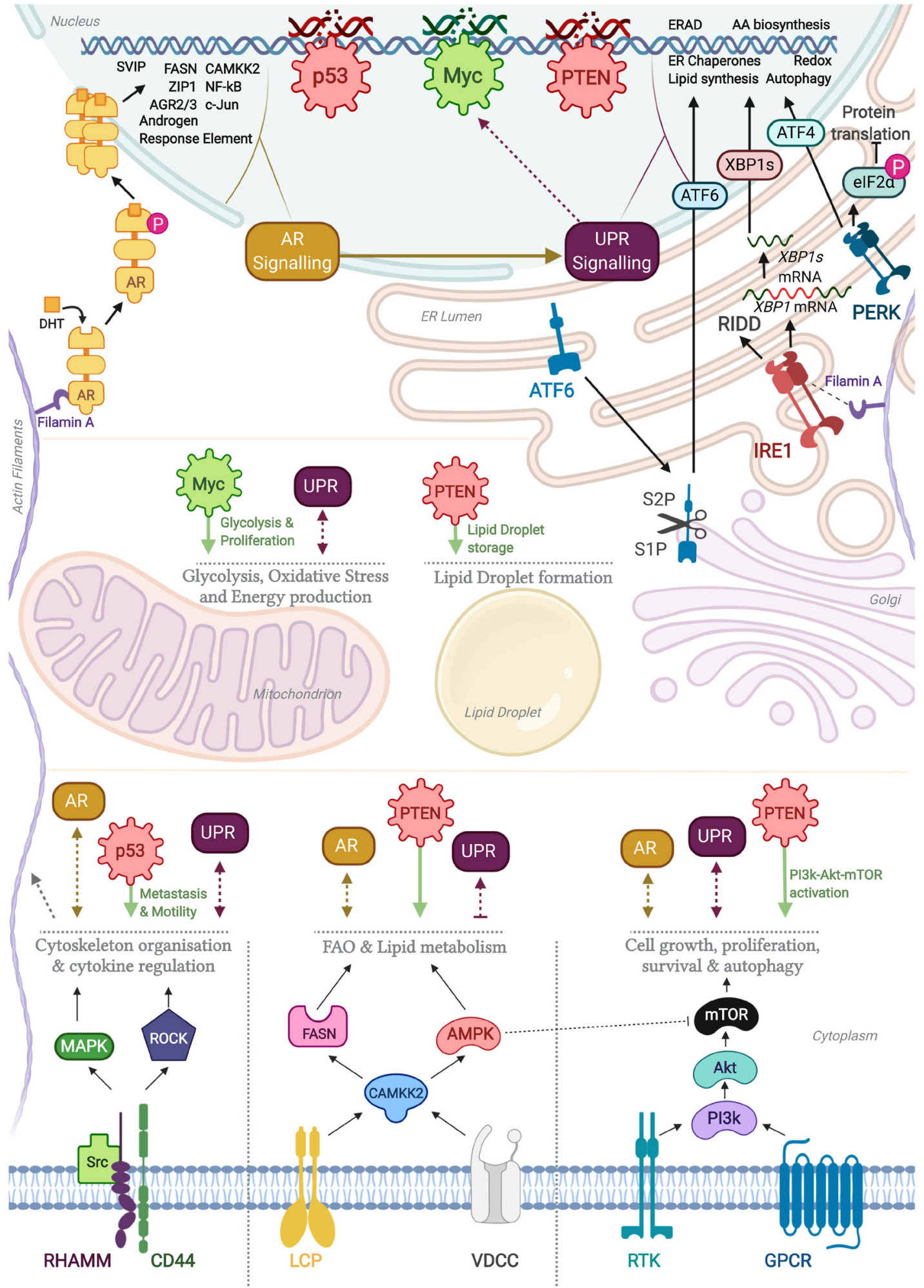

Figure 3

AR-UPR-oncogenic driver crosstalk in CRPC. Myc amplification (green) and PTEN, p53 loss (red) drive central mechanisms of CRPC development including (A) glycolysis and oxidative stress; (B) cytoskeletal organisation and metastasis; (C) lipid metabolism and (D) cell growth, proliferation and autophagy. The UPR (purple) is involved in all four mechanisms as well as inducing c-Myc itself, compounding PCa development. In parallel, AR signalling (mustard) drives UPR signalling while also being involved separately in all four wide mechanisms driving PCa growth. Evidence derived from such studies point to a synergistic relationship between oncogenic drivers of CRPC, the AR and the UPR. The nature of this synergy, be it reciprocal or convergent, remains to be elucidated. 
compared to normal epithelium, and in vivo murine experiments showed that inhibiting CAMKK2 resulted in tumoral growth inhibition as a result of its action as an AR regulator and stabiliser as well as a migration mediator through AMPK and glycolysis via the AMPK-PFK pathway (Fig. 2) (Dadwal et al. 2018). CAMKK2 has also been shown to promote prostate cancer independently of the AMPK pathway by affecting lipid metabolism. Indeed, loss of CAMKK2 reduced the expression of acetylcoA carboxylase and fatty acid synthase (FASN) which accompanied by an activation of AMPK showed decreased cell growth rates through inhibition of de novo lipogenesis. FASN was prominently upregulated in PTEN-null mice but was downregulated when CAMKK2 was inhibited in both PTEN-positive and PTEN-null backgrounds (Penfold et al. 2018). As such, it is evident that this calcium/calmodulin protein kinase has an effect on both lipid and calcium metabolism, is AR dependent and affects lipogenesis factors such as FASN whose inhibition have been shown to induce the UPR (Fig. 3) (Little et al. 2007). Further evidence of metabolic crosstalk between AR physiology and the UPR comes in the form of macrophage activation. CAMKK2 downregulation is detrimental to macrophage migration, cytokine and chemokine release and bacterial phagocytosis (Racioppi 2013), while high IRE1 activity was shown to be a major factor in macrophage recruitment towards another solid tumour, glioblastoma multiform (GBM) (Lhomond et al. 2018). The lipidic link to prostate cancer metastasis to bone sites has been further explored in the context of the ER stress response through studies showing that osteotrophic prostate tumour cells upregulated the HO-1 oxidative stress marker while at the same time upregulating BiP and XBP1s through lipid uptake in adipocyte rich environments (Herroon et al. 2018) (Fig. 3).

\section{Myc amplification is supported by UPR signalling}

Myc overexpression leads to an enhanced dependency on TCA cycle metabolites (Fig. 3), which include the products of processes such as beta-oxidation of lipids and glutamine consumption (Goetzman \& Prochownik 2018). Studies trying to discern these as resistance mechanisms have unveiled the E2F cell cycle regulator as the androgen independent driver of tumour growth accompanied by increased N-Myc activity (Handle et al. 2019). Interestingly, $\mathrm{N}-\mathrm{Myc}$ is very similar to c-Myc in function and structure and both play a role in prostatic neoplasia; however, c-Myc, one of the most highly activated pathways in PCa, has been shown to be dependent on IRE1-XBP1 axis function. Specifically, XBP1s is required for the activation of the c-Myc transcriptional programme, and there was co-localisation of c-Myc and XBP1s in human prostate cancer specimens pertaining to a positive feedback loop between UPR signalling, myc signalling and prostate tumorigenesis (Sheng et al. 2019) (Fig. 3).

\section{Other drivers of CRPC include cytoskeletal AR/UPR-related changes and UPR-centric hypoxic responses}

$\mathrm{p} 53 / \mathrm{Rb}$ loss induces the release of stress-induced checkpoint control and maintenance of cell cycling (p53/ $\mathrm{Rb}$ loss) (Sharma et al. 2007). This has been implicated in prostatic metastasis through the regulation of the RHAMM motility receptor which stabilises f-actin polymerisation through ROCK signalling (Thangavel et al. 2017). Such tumorigenic effects on the cytoskeleton have already been described to have direct impact both on UPR (Urra et al. 2018) and AR (Castoria et al. 2011) mediated metastasis through filamin A signalling (Fig. 3).

While there are a significant number of hypoxic gene signatures linked to CRPC and there is evidence in other cancer types of a direct relationship between HIF1 $\alpha$ and XBP1, the interplay between hypoxia and the UPR in prostate cancer is largely unexplored. We know, however, that there is a significant interplay with the AR and that hypoxia and HIF1 $\alpha$ have very significant impacts on metabolic function, which we would expect to be compensated for by changes in UPR activity. Chronic ADT administration in the presence of hypoxia actually induced adaptation to antiandrogen treatment via the increase of glucose 6 phosphate isomerase (GPI) brought about by AR inhibition. GPI restores glucose metabolism by favouring a hypoxic glycolytic activity that compounds adaptation to ADT. This interplay is further evidence of hypoxia and the AR controlling a metabolic switch that promotes CRPC development (Geng et al. 2018). HIF itself plays a central metabolic role evidenced by an overexpression of both HIF $1 \alpha$ and HIF $2 \alpha$ in the hypothalamus involved in both weight gain functions, glucose uptake and energy expenditure (Gaspar \& Velloso 2018). HIFs are also involved in lipid metabolism, as uptake of extracellular fatty acids and triglyceride synthesis are upregulated during hypoxia through PPARg activated by HIF1 which additionally mediates the expression of FABP3 and FABP4 in tumour cells (Mylonis et al. 2019).

Under hypoxic conditions in breast cancer, XBP1 induces miR-153 by binding onto the promoter of PTPRN 
which in turn directly inhibits the expression of HIF1 $\alpha$ and subsequently reduces the secretion of VEGFA to modulate angiogenesis (Liang et al. 2018). It has also been reported that HIF $1 \alpha$ levels are regulated by ER stress, while apoptotic processes are impacted by hypoxia and ER stress in a temporal manner (early and late, respectively) (Lõpez-Hernández et al. 2015). This could be of particular significance in metabolic disorders, as for slow growing tumours such as $\mathrm{PCa}$, the exact therapeutic window and which pathways to target during this window are of great importance to the efficacy of the therapy. Apart from hypoxia another event that miRNAs have been shown to be involved in, in the evolution of $\mathrm{PCa}$, is resistance to radiotherapy. Indeed miR-191 was found to be upregulated in PCa when compared to normal prostate tissue and correlated positively with higher Gleason scores. It produced these effects by interacting with retinoid $\mathrm{x}$ receptor alpha (RXRA) which is downregulated in PCa (Ray et al. 2020). Such involvement of miRNA in AR physiology, UPR biology and PCa pathophysiology highlights the potential importance of non-coding RNAs as biomarkers and possible therapeutic targets.

\section{Current and future perspectives on targeting the UPR in prostate cancer}

It is evident that the UPR and the AR are so interconnected that they present a valid therapeutic dual target in $\mathrm{PCa}$ and especially in CRPC where conventional ADT is having little to no effect. However, certain barriers to such an approach remain that predominantly have to do with patient stratification. After all, the target is to provide therapeutic solutions for a heterogenous group of patients by targeting a fine tuning mechanism that always oscillates around a homeostatic balance. This could perhaps dissuade from a 'one size fits all' approach where all patients are treated with the same combination of UPR/AR modulators. As such, biomarker development is key. Classifying cancers according to their UPR status is incredibly tricky due to the availability of material that these markers are derived from; in GBM, for example, the hugely aggressive nature of the tumour and its anatomical location make repeat biopsies impossible. This means that the transcriptional data derived from sequencing these tumours upon resection provide only a small, albeit valuable, window into the life time of the tumour and as such only give a snapshot of UPR status. This status could change as the disease evolves. Despite this drawback, some work has been carried out to generate activity signatures (to be distinguished from expression levels) of IRE1,
XBP1s and RIDD function by combining data mining and gene ontology enrichment strategies. These approaches were able to classify GBM patients according to their IRE1 status as well as their XBP1/RIDD status in four distinct groups showing that IRE1 and XBP1, in particular, is a tumorigenicity driver in GBM (Lhomond et al. 2018). Being able to distinguish between patients according to UPR status is of great importance considering the diverse role that the UPR plays in cancer physiology. As the UPR has been implicated in cancer stem biology (PeñarandaFajardo et al. 2019), it is possible that targeting the UPR in certain patients (depending on their UPR status) could affect cell populations that may be deleterious as, for example, a stem phenotypic change could lead to a more adaptive subpopulation of cells that promotes disease recurrence.

The advantage of studying prostate cancer in this instance is that the disease progression is relatively long with ample opportunity for sample collection including healthy tissue, malignant tissue, blood and urine. Since there are a plethora of biological materials to work with, one question that needs to be addressed is whether looking for a transcriptional UPR classification would be the most clinically relevant. Moreover, even if a proteomic approach is preferred due to its translational value in the clinic, would it be pertinent to select single protein biomarkers or is this a biology that truly requires a systems level approach? Considering that it is a complex biology with many upstream and downstream interactors, it seems that a systems approach is one of the most value. Of course, a caveat in this approach would require exceptionally well-annotated sample collections and models that represent the full spectrum of disease and diverse temporal disease evolution. There have been few attempts to classify prostate cancer using multiparametric profiling comparing proteomic, transcriptomic and genomic approaches. Interestingly, the conclusion of such a study was that EIF2/translational effects are more significant than previously appreciated when proteomics is performed as opposed to genomics or transcriptomics (Latonen et al. 2018).

Alternatively, a systems level approach may not be the ultimate destination but rather if it were possible to undertake a much careful functional analysis of the key proteins and transcripts that are dependent on UPR activation and confer pro-survival biologies, a robust set of activity biomarkers could be discovered alongside more selective and effective druggable targets. This has been the route taken to attempt to improve responses to AR-targeted therapies and improve the classification of 
prostate cancers moving beyond PSA as a marker (Eskra et al. 2019). Discerning UPR biomarkers poses a similar problem, although on a greater scale, because it has to address the potentially intersecting activities of a number of transcription factors which include the AR and XBP1/ ATF6/ATF4 as well as the downstream transcription factors under their influence. Given that complexity, it is increasingly attractive to investigate the UPR alongside the AR and try to identify major players at the intersection of these major signalling pathways. This may have wide reaching implications given that, in other cancer types such as TNBC, known AR targets such as CAMKK2 and major pathways such as myc are XBP1-HIF1 $\alpha$ dependent (Chen et al. 2014, Casciano et al. 2020). These transcription factors all require translocation/trafficking to control their activity and many require phosphorylation. Since both UPR transcription factors and the AR need to translocate to the nucleus, it is possible that they require the same cytoskeletal machinery to regulate their translocation (Castoria et al. 2011, Urra et al. 2018).

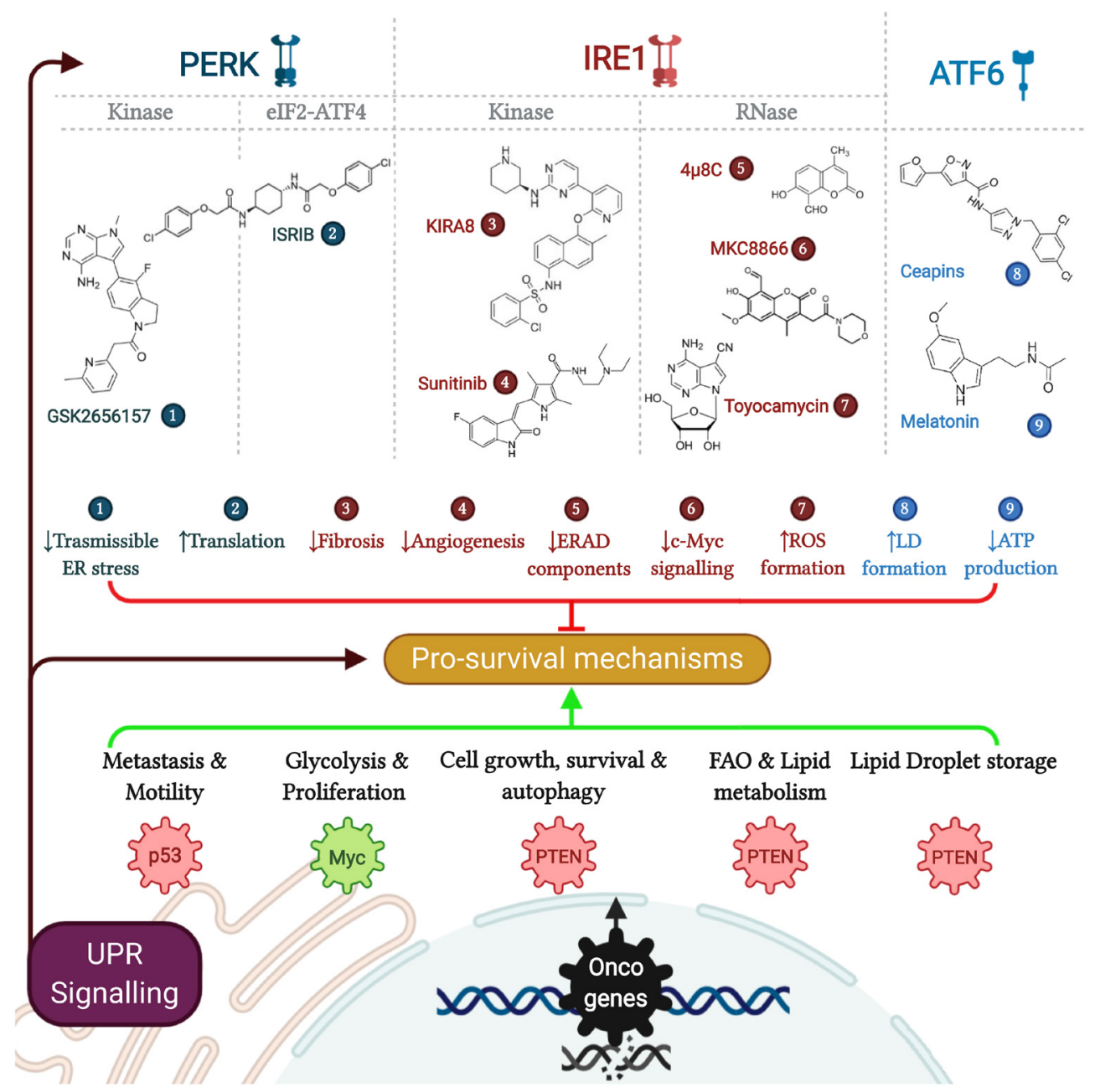

Figure 4

UPR pharmacological targeting and oncogenic driver crossover in CRPC. Non-exhaustive list of modulators targeting each of the three major transducers of the UPR mapping onto the pro-survival processes driven by CRPC oncogenic drivers and supported by the UPR. PERK inhibition (dark blue): GSK2656157 has been shown to decrease transmissible ER stress affecting metastasis, while ISRIB mediated PERK inhibition upregulates translation compounding anti-oncogenic misfolded protein mediated stress (Guthrie et al. 2016, Rodvold et al. 2017). IRE1 inhibition (Red): KIRAs have been shown to decrease fibrosis affecting motility (Thamsen et al. 2019), sunitinib has been investigated in clinical trials as an anti-angiogen (https://clinicaltrials.gov/ct2/ show/NCT03025893; Jha et al. 2011), while 4 $\mu 8 \mathrm{C}$ impacts autophagy by decreasing ERAD components (Erzurumlu \& Ballar 2017). MKC8866 was shown to block c-Myc signalling (Sheng et al. 2019) and toyocamycin lead to an upregulation of ROS formation impacting survival (Park et al. 2017) in prostate cancer models. ATF6 inhibition (Light blue): ceapins were found to upregulate lipid droplet formation (Gallagher \& Walter 2016), while melatonin was shown to block ATF6 as well as decreasing ATP production impacting metabolism (Hevia et al. 2017). These investigations are supported by ongoing studies pinpointing the value of targeting UPR activity as therapeutic interventions in PCa such as targeting the splicing machinery affecting XBP1 signalling (Jiménez-Vacas et al. 2020). 


\section{Conclusions}

CRPC is a major endocrinological malignancy with a significant public health burden. Although ADT treatments are effective in the vast majority of people with localised PCa, CRPC tumours often retain AR and UPR activity mechanisms shown to be governed by UPR activity - all the while maintaining an active AR physiology. So far, the literature has shown that the UPR is an attractive druggable target in multiple malignancies and a complex biochemical response that has significant overlap with AR physiology. As such, it is logical to deduce that UPR modulation is a significantly attractive therapeutic avenue in sensitising ADT resistant tumours to either conventional or novel therapeutic regimes. Although UPR modulation has shown significant anti-tumoral effects in various cancer models including AR-dependent ones such as PCa and breast cancer (Logue et al. 2018, Nguyen et al. 2018, Sheng et al. 2019), significant work has to occur for these results to be translatable in the clinic for the benefit of hugely heterogenous subject populations that are cancer patients.

Major considerations that may have to be addressed, before either dismissing or embracing the use of UPR targeting modulators (Fig. 4), include off-target effects and the ubiquitous nature of this homeostatic mechanism. Furthermore, the balancing act that the three transducers of the UPR continuously carry out which is a contributing factor to why ER stress modulators (inducers or inhibitors) may have failed at clinical trial level (Almanza et al. 2018). As discussed earlier in this review, different arms of the ER stress response may play more or less significant roles during disease evolution. As such, a robust, informed set of data and prognostic, diagnostic and bridging biomarkers are required to guide which patients and at what exact therapeutic window would benefit from targeting key functional pillars of AR and UPR physiology in order to maximise positive clinical output. The crux of this metabolic crosstalk will be to discern whether the AR-UPR synergy is reciprocal or convergent. If reciprocal, then UPR modulation could offer a route of sensitisation of CRPC to androgen therapies. If convergent, combinatorial targeting may well provide a more sustained response as, since multiple pathways are targeted, a synthetic lethality effect may be elicited.

\section{Declaration of interest}

The authors declare that there is no conflict of interest that could be perceived as prejudicing the impartiality of this review.
Funding

I G M and D D are funded by the John Black Charitable Foundation.

\section{References}

Almanza A, Carlesso A, Chintha C, Creedican S, Doultsinos D, Leuzzi B, Luís A, McCarthy N, Montibeller L, More S, et al. 2018 Endoplasmic reticulum stress signalling - from basic mechanisms to clinical applications. FEBS Journal 286 241-278. (https://doi.org/10.1111/ febs.14608)

Asim M, Tarish F, Zecchini HI, Sanjiv K, Gelali E, Massie CE, Baridi A, Warren AY, Zhao W, Ogris C, et al. 2017 Synthetic lethality between androgen receptor signalling and the PARP pathway in prostate cancer. Nature Communications 8 374. (https://doi.org/10.1038/ s41467-017-00393-y)

Barfeld SJ, Itkonen HM, Urbanucci A \& Mills IG 2014 Androgenregulated metabolism and biosynthesis in prostate cancer. EndocrineRelated Cancer 21 T57-T66. (https://doi.org/10.1530/ERC-13-0515)

Bennett NC, Gardiner RA, Hooper JD, Johnson DW \& Gobe GC 2010 Molecular cell biology of androgen receptor signalling. International Journal of Biochemistry and Cell Biology 42 813-827. (https://doi. org/10.1016/j.biocel.2009.11.013)

Bertolotti A, Zhang Y, Hendershot LM, Harding HP \& Ron D 2000 Dynamic interaction of BiP and ER stress transducers in the unfolded-protein response. Nature Cell Biology 2 326-332. (https:// doi.org/10.1038/35014014)

Bonkhoff H \& Remberger K 1993 Widespread distribution of nuclear androgen receptors in the basal cell layer of the normal and hyperplastic human prostate. Virchows Archiv: A, Pathological Anatomy and Histopathology 422 35-38. (https://doi.org/10.1007/ bf01605130)

Briggs JW, Ren L, Chakrabarti KR, Tsai YC, Weissman AM, Hansen RJ, Gustafson DL, Khan YA, Dinman JD \& Khanna C 2017 Activation of the unfolded protein response in sarcoma cells treated with rapamycin or temsirolimus. PLOS ONE 12 e0185089. (https://doi. org/10.1371/journal.pone.0185089)

Bu H, Schweiger MR, Manke T, Wunderlich A, Timmermann B, Kerick M, Pasqualini L, Shehu E, Fuchsberger C, Cato ACB, et al. 2013 Anterior gradient 2 and 3 - two prototype androgen-responsive genes transcriptionally upregulated by androgens and by oestrogens in prostate cancer cells. FEBS Journal 280 1249-1266. (https://doi. org/10.1111/febs.12118)

Casciano JC, Perry C, Cohen-Nowak AJ, Miller KD, Vande Voorde J, Zhang Q, Chalmers S, Sandison ME, Liu Q, Hedley A, et al. 2020 MYC regulates fatty acid metabolism through a multigenic program in claudin-low triple negative breast cancer. British Journal of Cancer 122 868-884. (https://doi.org/10.1038/s41416-019-0711-3)

Castoria G, D'Amato L, Ciociola A, Giovannelli P, Giraldi T, Sepe L, Paolella G, Barone MV, Migliaccio A \& Auricchio F 2011 Androgeninduced cell migration: role of androgen receptor/filamin A association. PLOS ONE 6 e17218. (https://doi.org/10.1371/journal. pone.0017218)

Chen X, Iliopoulos D, Zhang Q, Tang Q, Greenblatt MB, Hatziapostolou M, Lim E, Tam WL, Ni M, Chen Y, et al. 2014 XBP1 promotes triple-negative breast cancer by controlling the HIF1alpha pathway. Nature 508 103-107. (https://doi.org/10.1038/nature13119)

Cheng X, Liu H, Jiang CC, Fang L, Chen C, Zhang XD \& Jiang ZW 2014 Connecting endoplasmic reticulum stress to autophagy through IRE1/JNK/beclin-1 in breast cancer cells. International Journal of Molecular Medicine 34 772-781. (https://doi.org/10.3892/ ijmm.2014.1822)

Costello LC \& Franklin RB 2000 The intermediary metabolism of the prostate: a key to understanding the pathogenesis and progression of 
prostate malignancy. Oncology 59 269-282. (https://doi. org/10.1159/000012183)

Cultrara CN, Kozuch SD, Ramasundaram P, Heller CJ, Shah S, Beck AE, Sabatino D \& Zilberberg J 2018 GRP78 modulates cell adhesion markers in prostate cancer and multiple myeloma cell lines. BMC Cancer 18 1263. (https://doi.org/10.1186/s12885-018-5178-8)

Cutruzzolà F, Giardina G, Marani M, Macone A, Paiardini A, Rinaldo S \& Paone A 2017 Glucose metabolism in the progression of prostate cancer. Frontiers in Physiology 8 97. (https://doi.org/10.3389/ fphys.2017.00097)

Dadey DYA, Kapoor V, Khudanyan A, Urano F, Kim AH, Thotala D \& Hallahan DE 2016 The ATF6 pathway of the ER stress response contributes to enhanced viability in glioblastoma. Oncotarget 7 2080-2092. (https://doi.org/10.18632/oncotarget.6712)

Dadwal UC, Chang ES \& Sankar U 2018 Androgen receptor-CaMKK2 axis in prostate cancer and bone microenvironment. Frontiers in Endocrinology 9 335. (https://doi.org/10.3389/fendo.2018.00335)

DeZwaan-McCabe D, Sheldon RD, Gorecki MC, Guo DF, Gansemer ER, Kaufman RJ, Rahmouni K, Gillum MP, Taylor EB, Teesch LM, et al. 2017 ER stress inhibits liver fatty acid oxidation while unmitigated stress leads to anorexia-induced lipolysis and both liver and kidney steatosis. Cell Reports 19 1794-1806. (https://doi.org/10.1016/j. celrep.2017.05.020)

Doultsinos D, Avril T, Lhomond S, Dejeans N, Guédat P \& Chevet E 2017 Control of the unfolded protein response in health and disease. SLAS Discovery 22 787-800. (https://doi. org $/ 10.1177 / 2472555217701685$ )

Edlind MP \& Hsieh AC 2014 PI3K-AKT-mTOR signaling in prostate cancer progression and androgen deprivation therapy resistance. Asian Journal of Andrology 16 378-386. (https://doi.org/10.4103/1008682X.122876)

Eidelman E, Twum-Ampofo J, Ansari J \& Siddiqui MM 2017 The metabolic phenotype of prostate cancer. Frontiers in Oncology 7131. (https://doi.org/10.3389/fonc.2017.00131)

Eletto D, Eletto D, Dersh D, Gidalevitz T \& Argon Y 2014 Protein disulfide isomerase A6 controls the decay of IRE1 $\alpha$ signaling via Disulfide-Dependent Association. Molecular Cell 53 562-576. (https:// doi.org/10.1016/j.molcel.2014.01.004)

Erzurumlu Y \& Ballar P 2017 Androgen mediated regulation of endoplasmic reticulum-associated degradation and its effects on prostate cancer. Scientific Reports 7 40719. (https://doi.org/10.1038/ srep40719)

Eskra JN, Rabizadeh D, Pavlovich CP, Catalona WJ \& Luo J 2019 Approaches to urinary detection of prostate cancer. Prostate Cancer and Prostatic Diseases 22 362-381. (https://doi.org/10.1038/s41391019-0127-4)

Flaherty DP, Miller JR, Garshott DM, Hedrick M, Gosalia P, Li Y, Milewski M, Sugarman E, Vasile S, Salaniwal S, et al. 2014 Discovery of sulfonamidebenzamides as selective apoptotic CHOP pathway activators of the unfolded protein response. ACS Medicinal Chemistry Letters 5 1278-1283. (https://doi.org/10.1021/ml5003234)

Gallagher CM \& Walter P 2016 Ceapins inhibit ATF6 $\alpha$ signaling by selectively preventing transport of ATF6 $\alpha$ to the Golgi apparatus during ER stress. eLife 5 e11880. (https://doi.org/10.7554/ eLife.11880)

Garcia MA, Gil J, Ventoso I, Guerra S, Domingo E, Rivas C \& Esteban M 2006 Impact of protein kinase PKR in cell biology: from antiviral to antiproliferative action. Microbiology and Molecular Biology Reviews 70 1032-1060. (https://doi.org/10.1128/MMBR.00027-06)

Gaspar JM \& Velloso LA 2018 Hypoxia inducible factor as a central regulator of metabolism - implications for the development of obesity. Frontiers in Neuroscience 12 813. (https://doi.org/10.3389/ fnins.2018.00813)

Geng H, Xue C, Mendonca J, Sun XX, Liu Q, Reardon PN, Chen Y, Qian K, Hua V, Chen A, et al. 2018 Interplay between hypoxia and androgen controls a metabolic switch conferring resistance to
androgen/AR-targeted therapy. Nature Communications 94972. (https://doi.org/10.1038/s41467-018-07411-7)

Goetzman ES \& Prochownik EV 2018 The role for myc in coordinating glycolysis, oxidative phosphorylation, glutaminolysis, and fatty acid metabolism in normal and neoplastic tissues. Frontiers in Endocrinology 9 129. (https://doi.org/10.3389/fendo.2018.00129)

Gorlov IP, Byun J, Gorlova OY, Aparicio AM, Efstathiou E \& Logothetis CJ 2009 Candidate pathways and genes for prostate cancer: a meta-analysis of gene expression data. BMC Medical Genomics 2 48. (https://doi.org/10.1186/1755-8794-2-48)

Grasso CS, Wu YM, Robinson DR, Cao X, Dhanasekaran SM, Khan AP, Quist MJ, Jing X, Lonigro RJ, Brenner JC, et al. 2012 The mutational landscape of lethal castration-resistant prostate cancer. Nature $\mathbf{4 8 7}$ 239-243. (https://doi.org/10.1038/nature11125)

Grey MJ, Cloots E, Simpson MS, LeDuc N, Serebrenik YV, De Luca H, De Sutter D, Luong P, Thiagarajah JR, Paton AW, et al. 2020 IRE1 $\beta$ negatively regulates IRE1 $\alpha$ signaling in response to endoplasmic reticulum stress. Journal of Cell Biology 219 e201904048. (https://doi. org/10.1083/jcb.201904048)

Guthrie LN, Abiraman K, Plyler ES, Sprenkle NT, Gibson SA, McFarland BC, Rajbhandari R, Rowse AL, Benveniste EN \& Meares GP 2016 Attenuation of PKR-like ER kinase (PERK) signaling selectively controls endoplasmic reticulum stress-induced inflammation without compromising immunological responses. Journal of Biological Chemistry 291 15830-15840. (https://doi. org/10.1074/jbc.M116.738021)

Handle F, Prekovic S, Helsen C, Van den Broeck T, Smeets E, Moris L, Eerlings R, El Kharraz SE, Urbanucci A, Mills IG, et al. 2019 Drivers of AR indifferent anti-androgen resistance in prostate cancer cells. Scientific Reports 9 13786. (https://doi.org/10.1038/s41598-019-50220-1)

Hansen KG, Aviram N, Laborenz J, Bibi C, Meyer M, Spang A, Schuldiner M \& Herrmann JM 2018 An ER surface retrieval pathway safeguards the import of mitochondrial membrane proteins in yeast. Science 361 1118-1122. (https://doi.org/10.1126/science.aar8174)

Heinlein CA \& Chang C 2004 Androgen receptor in prostate cancer. Endocrine Reviews 25 276-308. (https://doi.org/10.1210/er.2002-0032)

Herroon MK, Rajagurubandara E, Diedrich JD, Heath EI \& Podgorski I 2018 Adipocyte-activated oxidative and ER stress pathways promote tumor survival in bone via upregulation of heme oxygenase 1 and survivin. Scientific Reports 8 40. (https://doi.org/10.1038/s41598-01717800-5)

Hetz C, Chevet E \& Harding HP 2013 Targeting the unfolded protein response in disease. Nature Reviews: Drug Discovery 12 703-719. (https://doi.org/10.1038/nrd3976)

Hevia D, Gonzalez-Menendez P, Fernandez-Fernandez M, Cueto S, Rodriguez-Gonzalez P, Garcia-Alonso JI, Mayo JC \& Sainz RM 2017 Melatonin decreases glucose metabolism in prostate cancer cells: a 13C stable isotope-resolved metabolomic study. International Journal of Molecular Sciences 18 E1620. (https://doi.org/10.3390/ ijms18081620)

Hoffman RM 2011 Clinical practice. Screening for prostate cancer. New England Journal of Medicine 365 2013-2019. (https://doi.org/10.1056/ NEJMcp1103642)

Hollien J, Lin JH, Li H, Stevens N, Walter P \& Weissman JS 2009 Regulated Ire1-dependent decay of messenger RNAs in mammalian cells. Journal of Cell Biology 186 323-331. (https://doi.org/10.1083/ jcb.200903014)

Hussain M, Fizazi K, Saad F, Rathenborg P, Shore N, Ferreira U, Ivashchenko P, Demirhan E, Modelska K, Phung D, Krivoshik A, Sternberg CN 2018 Enzalutamide in men with nonmetastatic, castration-resistant prostate cancer. New England Journal of Medicine 378 2465-2474. (https://doi.org/10.1056/NEJMoa1800536)

Imagawa Y, Hosoda A, Sasaka Si, Tsuru A \& Kohno K 2008 RNase domains determine the functional difference between IRE1 $\alpha$ and IRE1ß. FEBS Letters 582 656-660. (https://doi.org/10.1016/j. febslet.2008.01.038) 
Jha BK, Polyakova I, Kessler P, Dong B, Dickerman B, Sen GC \& Silverman RH 2011 Inhibition of RNase L and RNA-dependent protein kinase (PKR) by sunitinib impairs antiviral innate immunity. Journal of Biological Chemistry 286 26319-26326. (https://doi. org/10.1074/jbc.M111.253443)

Jiménez-Vacas JM, Herrero-Aguayo V, Montero-Hidalgo AJ, GómezGómez E, Fuentes-Fayos AC, León-González AJ, Sáez-Martínez P, Alors-Pérez E, Pedraza-Arévalo S, González-Serrano T, et al. 2020 Dysregulation of the splicing machinery is directly associated to aggressiveness of prostate cancer. EBioMedicine $\mathbf{5 1}$ 102547. (https:// doi.org/10.1016/j.ebiom.2019.11.008)

Kaarbø M, Mikkelsen OL, Malerød L, Qu S, Lobert VH, Akgul G, Halvorsen T, Mælandsmo GM \& Saatcioglu F 2010 PI3K-AKT-mTOR pathway is dominant over androgen receptor signaling in prostate cancer cells. Cellular Oncology 32 11-27. (https://doi.org/10.3233/ CLO-2009-0487)

Kapuy O, Vinod PK \& Bánhegyi G 2014 MTOR inhibition increases cell viability via autophagy induction during endoplasmic reticulum stress - an experimental and modeling study. FEBS Open Bio 4 704-713. (https://doi.org/10.1016/j.fob.2014.07.006.

Kruse KB, Brodsky JL \& McCracken AA 2006 Autophagy: an ER protein quality control process. Autophagy 2 135-137.

Latonen L, Afyounian E, Jylhä A, Nättinen J, Aapola U, Annala M, Kivinummi KK, Tammela TTL, Beuerman RW, Uusitalo H, et al. 2018 Integrative proteomics in prostate cancer uncovers robustness against genomic and transcriptomic aberrations during disease progression. Nature Communications 9 1176. (https://doi.org/10.1038/ s41467-018-03573-6)

Lee KP, Dey M, Neculai D, Cao C, Dever TE \& Sicheri F 2008 Structure of the dual enzyme Ire1 reveals the basis for catalysis and regulation in nonconventional RNA splicing. Cell 132 89-100. (https://doi. org/10.1016/j.cell.2007.10.057)

Lhomond S, Avril T, Dejeans N, Voutetakis K, Doultsinos D, McMahon M, Pineau R, Obacz J, Papadodima O, Jouan F, et al. 2018 Dual IRE1 RNase functions dictate glioblastoma development. EMBO Molecular Medicine 10 139-308. (https://doi.org/10.15252/ emmm.201707929)

Liang H, Xiao J, Zhou Z, Wu J, Ge F, Li Z, Zhang H, Sun J, Li F, Liu R, et al. 2018 Hypoxia induces MIR-153 through the IRE1 $\alpha$-XBP1 pathway to fine tune the HIF1 $\alpha /$ VEGFA axis in breast cancer angiogenesis. Oncogene 37 1961-1975. (https://doi.org/10.1038/ s41388-017-0089-8)

Little JL, Wheeler FB, Fels DR, Koumenis C \& Kridel SJ 2007 Inhibition of fatty acid synthase induces endoplasmic reticulum stress in tumor cells. Cancer Research 67 1262-1269. (https://doi.org/10.1158/00085472.CAN-06-1794)

Logue SE, McGrath EP, Cleary P, Greene S, Mnich K, Almanza A, Chevet E, Dwyer RM, Oommen A, Legembre P, et al. 2018 Inhibition of IRE1 RNase activity modulates the tumor cell secretome and enhances response to chemotherapy. Nature Communications 93267. (https://doi.org/10.1038/s41467-018-05763-8)

Lõpez-Hernández B, Ceña V \& Posadas I 2015 The endoplasmic reticulum stress and the HIF-1 signalling pathways are involved in the neuronal damage caused by chemical hypoxia. British Journal of Pharmacology 172 2838-2851. (https://doi.org/10.1111/bph.13095)

Martino MB, Jones L, Brighton B, Ehre C, Abdulah L, Davis CW, Ron D, O'Neal WK, Ribeiro CMPP 2013 The ER stress transducer IRE1 $\beta$ is required for airway epithelial mucin production. Mucosal Immunology 6 639-654. (https://doi.org/10.1038/mi.2012.105)

Massie CE, Lynch A, Ramos-Montoya A, Boren J, Stark R, Fazli L, Warren A, Scott H, Madhu B, Sharma N, et al. 2011 The androgen receptor fuels prostate cancer by regulating central metabolism and biosynthesis. EMBO Journal 30 2719-2733. (https://doi.org/10.1038/ emboj.2011.158)

Maurel M, Obacz J, Avril T, Ding YP, Papadodima O, Treton X, Daniel F, Pilalis E, Hörberg J, Hou W, et al. 2019 Control of anterior GRadient
2 (AGR2) dimerization links endoplasmic reticulum proteostasis to inflammation. EMBO Molecular Medicine 11 e10120. (https://doi. org/10.15252/emmm.201810120)

Mylonis I, Simos G \& Paraskeva E 2019 Hypoxia-inducible factors and the regulation of lipid metabolism. Cells 8 214. (https://doi. org/10.3390/cells8030214)

Nguyen HG, Conn CS, Kye Y, Xue L, Forester CM, Cowan JE, Hsieh AC, Cunningham JT, Truillet C, Tameire F, et al. 2018 Development of a stress response therapy targeting aggressive prostate cancer. Science Translational Medicine 10 eaar2036. (https://doi.org/10.1126/ scitranslmed.aar2036)

Obacz J, Sommerova L, Sicari D, Durech M, Avril T, Iuliano F, Pastorekova S, Hrstka R, Chevet E, Delom F, et al. 2019 Extracellular AGR3 regulates breast cancer cells migration via Src signaling. Oncology Letters 18 4449-4456. (https://doi.org/10.3892/ ol.2019.10849)

Pakos-Zebrucka K, Koryga I, Mnich K, Ljujic M, Samali A \& Gorman AM 2016 The integrated stress response. EMBO Reports 17 1374-1395. (https://doi.org/10.15252/embr.201642195)

Park SG, Kim SH, Kim KY, Yu SN, Choi HD, Kim YW, Nam HW, Seo YK \& Ahn SC 2017 Toyocamycin induces apoptosis via the crosstalk between reactive oxygen species and p38/ERK MAPKs signaling pathway in human prostate cancer PC-3 cells. Pharmacological Reports 69 90-96. (https://doi.org/10.1016/j.pharep.2016.10.014)

Peñaranda-Fajardo NM, Meijer C, Liang Y, Dijkstra BM, AguirreGamboa R, den Dunnen WFA \& Kruyt FAE 2019 ER stress and UPR activation in glioblastoma: identification of a noncanonical PERK mechanism regulating GBM stem cells through SOX2 modulation. Cell Death and Disease 10 690. (https://doi.org/10.1038/s41419-019. 1934-1)

Penfold L, Woods A, Muckett P, Nikitin AY, Kent TR, Zhang S, Graham R, Pollard A \& Carling D 2018 CaMKK2 promotes prostate cancer independently of AMPK via increased lipogenesis. Cancer Research 78 6747-6761. (https://doi.org/10.1158/0008-5472.CAN-180585)

Proverbs-Singh T, Feldman JL, Morris MJ, Autio KA \& Traina TA 2015 Targeting the androgen receptor in prostate and breast cancer: several new agents in development. Endocrine-Related Cancer 22 R87-R106. (https://doi.org/10.1530/ERC-14-0543)

Racioppi L 2013 CaMKK2: a novel target for shaping the androgenregulated tumor ecosystem. Trends in Molecular Medicine 19 83-88. (https://doi.org/10.1016/j.molmed.2012.12.004)

Rajesh K, Krishnamoorthy J, Kazimierczak U, Tenkerian C, Papadakis AI, Wang S, Huang S \& Koromilas AE 2015 Phosphorylation of the translation initiation factor eIF $2 \alpha$ at serine 51 determines the cell fate decisions of Akt in response to oxidative stress. Cell Death and Disease 6 e1591. (https://doi.org/10.1038/cddis.2014.554)

Ranasinghe WKB, Xiao L, Kovac S, Chang M, Michiels C, Bolton D, Shulkes A, Baldwin GS \& Patel O 2013 The role of hypoxia-inducible factor $1 \alpha$ in determining the properties of castrate-resistant prostate cancers. PLoS One 8 e54251. (https://doi.org/10.1371/journal. pone.0054251)

Ray J, Haughey C, Hoey C, Jeon J, Murphy R, Dura-Perez L, McCabe N, Downes M, Jain S, Boutros PC, et al. 2020 miR-191 promotes radiation resistance of prostate cancer through interaction with RXRa. Cancer Letters 473 107-117. (https://doi.org/10.1016/j. canlet.2019.12.025)

Renty BF 2014. Evidence that human prostate cancer is a ZIP1-deficient malignancy that could be effectively treated with a zinc ionophore (clioquinol) approach. Chemotherapy 4 152. (https://doi. org/10.4172/2167-7700.1000152)

Rodvold JJ, Chiu KT, Hiramatsu N, Nussbacher JK, Galimberti V, Mahadevan NR, Willert K, Lin JH \& Zanetti M 2017 Intercellular transmission of the unfolded protein response promotes survival and drug resistance in cancer cells. Science Signaling 10 eaah7177. (https://doi.org/10.1126/scisignal.aah7177) 
Rothe M, Sarma V, Dixit VM \& Goeddel DV 1995 TRAF2-mediated activation of NF-кB by TNF receptor 2 and CD40. Science 269 1424-1427. (https://doi.org/10.1126/science.7544915)

Sanchez-Alvarez M, Del Pozo MA \& Bakal C 2017 AKT-mTOR signaling modulates the dynamics of IRE1 RNase activity by regulating ER-mitochondria contacts. Scientific Reports 7 16497. (https://doi. org/10.1038/s41598-017-16662-1)

Sharma A, Comstock CES, Knudsen ES, Cao KH, Hess-Wilson JK, Morey LM, Barrera J \& Knudsen KE 2007 Retinoblastoma tumor suppressor status is a critical determinant of therapeutic response in prostate cancer cells. Cancer Research 67 6192-6203. (https://doi. org/10.1158/0008-5472.CAN-06-4424)

Sheng X, Nenseth HZ, Qu S, Kuzu OF, Frahnow T, Simon L, Greene S, Zeng Q, Fazli L, Rennie PS, et al. 2019 IRE1 $\alpha$-XBP1s pathway promotes prostate cancer by activating c-MYC signaling. Nature Communications 10 323. (https://doi.org/10.1038/s41467-018-08152-3)

Statz CM, Patterson SE \& Mockus SM 2017 mTOR inhibitors in castration-resistant prostate cancer: a systematic review. Targeted Oncology 12 47-59. (https://doi.org/10.1007/s11523-016-0453-6)

Storm M, Sheng X, Arnoldussen YJ \& Saatcioglu F 2016 Prostate cancer and the unfolded protein response. Oncotarget 7 54051-54066. (https://doi.org/10.18632/oncotarget.9912)

Tasdemir E, Maiuri MC, Orhon I, Kepp O, Morselli E, Criollo A \& Kroemer G 2008 p53 represses autophagy in a cell cycle-dependent fashion. Cell Cycle 7 3006-3011.

Tcherpakov M, Delaunay A, Toth J, Kadoya T, Petroski MD \& Ronai ZA 2009 Regulation of endoplasmic reticulum-associated degradation by RNF5-dependent ubiquitination of JNK-associated membrane protein (JAMP). Journal of Biological Chemistry 284 12099-12109. (https://doi. org/10.1074/jbc.M808222200)

Tenkerian C, Krishnamoorthy J, Mounir Z, Kazimierczak U, Khoutorsky A, Staschke KA, Kristof AS, Wang S, Hatzoglou M \& Koromilas AE 2015 MTORC2 balances AKT activation and eIF2 $\alpha$ serine 51 phosphorylation to promote survival under stress. Molecular Cancer Research 13 1377-1388. (https://doi. org/10.1158/1541-7786.MCR-15-0184-T)

Thamsen M, Ghosh R, Auyeung VC, Brumwell A, Chapman HA, Backes BJ, Perara G, Maly DJ, Sheppard D \& Papa FR 2019 Small molecule inhibition of IRE1 $\alpha$ kinase/RNase has anti-fibrotic effects in the lung. PLoS ONE 14 e0209824. (https://doi.org/10.1371/journal. pone.0209824)

Thangavel C, Boopathi E, Liu Y, Haber A, Ertel A, Bhardwaj A, Addya S, Williams N, Ciment SJ, Cotzia P, et al. 2017 RB loss promotes prostate cancer metastasis. Cancer Research 77 982-995. (https://doi. org/10.1158/0008-5472.CAN-16-1589)

Urano F, Wang XZ, Bertolotti A, Zhang Y, Chung P, Harding HP \& Ron D 2000 Coupling of stress in the ER to activation of JNK protein kinases by transmembrane protein kinase IRE1. Science 287 664-666. (https://doi.org/10.1126/science.287.5453.664)

Urra H, Dufey E, Avril T, Chevet E \& Hetz C 2016 Endoplasmic reticulum stress and the hallmarks of cancer. Trends in Cancer 2 252-262. (https://doi.org/10.1016/j.trecan.2016.03.007)

Urra H, Henriquez DR, Cánovas J, Villarroel-Campos D, CarrerasSureda A, Pulgar E, Molina E, Hazari YM, Limia CM, Alvarez-Rojas S, et al. 2018 IRE1 $\alpha$ governs cytoskeleton remodelling and cell migration through a direct interaction with filamin A. Nature Cell Biology 20 942-953. (https://doi.org/10.1038/s41556-018-0141-0)

Vriens K, Christen S, Parik S, Broekaert D, Yoshinaga K, Talebi A, Dehairs J, Escalona-Noguero C, Schmieder R, Cornfield T, et al. 2019 Evidence for an alternative fatty acid desaturation pathway increasing cancer plasticity. Nature 566 403-406. (https://doi. org/10.1038/s41586-019-0904-1)

Xia X, Lei L, Qin W, Wang L, Zhang G \& Hu J 2018 GCN2 controls the cellular checkpoint: potential target for regulating inflammation. Cell Death Discovery 4 20. (https://doi.org/10.1038/s41420-0170022-5)

Xu R \& Hu J 2020 The role of JNK in prostate cancer progression and therapeutic strategies. Biomedicine and Pharmacotherapy 121109679. (https://doi.org/10.1016/j.biopha.2019.109679)

Yang YC, Fu HC, Hsiao BL, Sobue G, Adachi H, Huang FJ, Hsuuw YD, Wei KT, Chang C, Huang KE, et al. 2013 Androgen receptor inclusions acquire GRP78/BiP to ameliorate androgen-induced protein misfolding stress in embryonic stem cells. Cell Death and Disease 4 e607. (https://doi.org/10.1038/cddis.2013.122)

Ye J, Kumanova M, Hart LS, Sloane K, Zhang H, De Panis DN, Bobrovnikova-Marjon E, Diehl JA, Ron D \& Koumenis C 2010 The GCN2-ATF4 pathway is critical for tumour cell survival and proliferation in response to nutrient deprivation. EMBO Journal 29 2082-2096. (https://doi.org/10.1038/emboj.2010.81)

Yue S, Li J, Lee SY, Lee HJ, Shao T, Song B, Cheng L, Masterson TA, Liu X, Ratliff TL, et al. 2014 Cholesteryl ester accumulation induced by PTEN loss and PI3K/AKT activation underlies human prostate cancer aggressiveness. Cell Metabolism 19 393-406. (https://doi. org/10.1016/j.cmet.2014.01.019)

Zhang L, Altuwaijri S, Deng F, Chen L, Lal P, Bhanot UK, Korets R, Wenske S, Lilja HG, Chang C, et al. 2009 NF-кB regulates androgen receptor expression and prostate cancer growth. American Journal of Pathology 175 489-499. (https://doi.org/10.2353/ ajpath.2009.080727)

Zhu X, Zhang J, Sun H, Jiang C, Dong Y, Shan Q, Su S, Xie Y, Xu N, Lou X, et al. 2014 Ubiquitination of inositol-requiring Enzyme 1 (IRE1) by the E3 ligase CHIP mediates the IRE1/TRAF2/JNK pathway. Journal of Biological Chemistry 289 30567-30577. (https://doi. org/10.1074/jbc.M114.562868)

Received in final form 16 April 2020

Accepted 24 April 2020

Accepted Manuscript published online 24 April 2020 (c) 2020 Society for Endocrinology Published by Bioscientifica Ltd. Printed in Great Britain 